\title{
DIRECT ULTRASOUND SYNTHESIS OF VANADYL PYROPHOSPHATE CATALYST FOR PARTIAL OXIDATION OF $N$-ButANE TO MALEIC ANHYDRIDE
}

\author{
Goo Kang Zhi \\ Department of Chemical Engineering \\ Universiti Tunku Abdul Rahman \\ Malaysia \\ Yap Yeow Hong \\ Department of Chemical Engineering \\ Universiti Tunku Abdul Rahman \\ Malaysia
}

\section{Lin Kuen-Song}

Department of Chemical Engineering and Materials Science/Environmental Technology

Research Center

Yuan Ze University

Taiwan

\section{Chiang Chao-Lung}

Department of Chemical Engineering and Materials Science/Environmental Technology

Research Center

Yuan Ze University

Taiwan

\section{Leong Loong Kong *}

Department of Chemical Engineering

Universiti Tunku Abdul Rahman

Malaysia

*Corrosponding author's Email: leonglk@utar.edu.my 


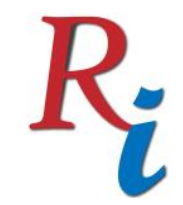

\section{Science Proceedings Series (SPS) \\ www.readersinsight.net/SPS}

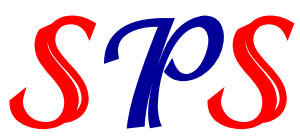

\section{R E S E A R C H H I G H L I G H T S}

This research revealed that the vanadyl pyrophosphate catalysts can be produced using direct ultrasound irradiation technique throughout the whole synthesis process. The findings indicated that the ultrasound produced catalysts gave higher activity and selectivity to maleic anhydride by showing smaller particle sizes, polycrystalline phase, increased of $\mathrm{V}^{5+}$ contribution, higher removal of oxygen species during reactivity testing compared to bulk catalysts. The ultrasound technique further showed significant reduction in catalyst production time from 48 hours to only 2 hours.

Keywords: Ultrasound Synthesis, Vanadyl Pyrophosphate Catalyst, Organic, Dihydrate, Sesquihydrat

\section{G R A P H I C A L A B S TR A C T}

Highly crystallised vanadyl pyrophosphates were synthesised from vanadium pentoxide by different routes via direct ultrasound irradiation synthesis process. The effect of direct ultrasound onto different preparation route towards the physico-chemical properties, reactivity and catalytic performances of the VPO catalysts is reported.
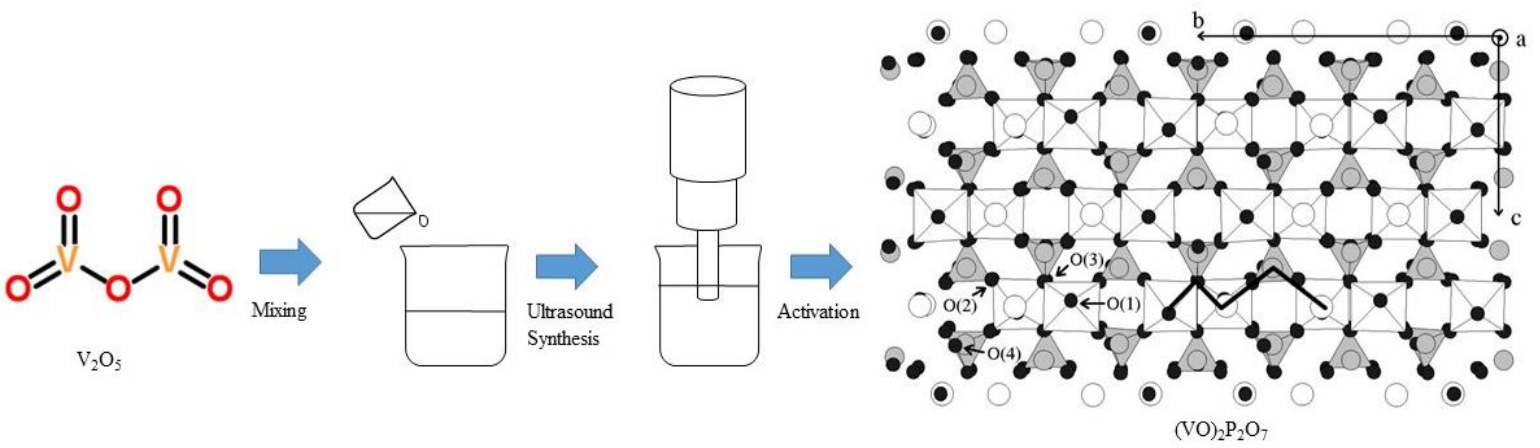

\section{RESEARCH OBJECTIVES}

As the conventional catalyst production methods still show limitation such as high preparation time, limited catalystic performances and etc. Therefore this research aims to imply an alternative energy source in developing catalyst faster and cost-efficient. Up to few years ago, use of ultrasound technique in chemistry was mainly domain in physical and polymer chemistry. The situation has now changed as the ultrasound technique is discovered to be not only enhance reaction rates but also direct reactions onto different pathways due to its acoustic cavitation effect. Thus, this research further examines the effect of ultrasound on physicochemical properties, reactivity and catalytic performances on the catalysts.

\section{MATERIALS AND METHODS}

Three VPO catalysts were prepared via direct ultrasound technique using organic, sesquihydrate and dihydrate routes (1-5), denoted as VPOuo, VPOus and VPOud respectively. These catalysts were synthesised solely on direct ultrasound technique and calcined in $n$ butane/air mixture. The physico-chemical, reactivity and catalytic properties of the vanadyl pyrophosphate catalysts synthesised via direct ultrasound synthesis were characterised by using X-ray diffraction (XRD), X-ray photoelectron spectroscopy (XPS), chemical analyses, field emission scanning electron microscope (FE-SEM), high resolution transmission electron microscope (HR-TEM), XANES spectra and temperature-programmed reduction $\left(\mathrm{H}_{2}-\mathrm{TPR}\right)$. 


\section{$R_{i}$}

\section{Science Proceedings Series (SPS) \\ www.readersinsight.net/SPS}

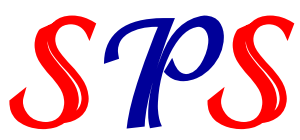

The effect of direct ultrasound onto different preparation route towards the physico-chemical properties, reactivity and catalytic performances of the VPO catalysts were examined.

\section{RESULTS}

All ultrasound produced catalysts exhibited well-crystallised $(\mathrm{VO})_{2} \mathrm{P}_{2} \mathrm{O}_{7}$ phase $(1,3,5,6)$. VPOus and VPOud showed $\alpha_{\mathrm{II}}-\mathrm{VOPO}_{4}$, which led to an increase in average oxidation state of vanadium $(3,5)$. The ultrasound produced catalysts were showing $\mathrm{O} 1 \mathrm{~s}$ approx. $530 \mathrm{eV}$, similar $\mathrm{P} 2 \mathrm{p}$ value and $\mathrm{V} 2 \mathrm{p}_{3 / 2}$ at approx. $517 \mathrm{eV}$, giving vanadium oxidation state of approx. $4.0-4.2$. FE-SEM micrographs showed the secondary structure consisting of thin plate-like crystals in different sizes agglomerate to each other due to cavitation effect $(4,6)$. HR-TEM demonstrated the existence of polycrystalline phase. The nature of the oxidants was investigated by TPR in $\mathrm{H}_{2}$. VPOus showed highest amount of total removal of oxygen species suggesting that it had highest activity compared to VPOuo and VPOud. The XANES measurement of these catalysts showed the occurrence of vanadium oxide reductions in flowing hydrogen gas, which indicates the presence of $\mathrm{V}^{4+}$ and $\mathrm{V}^{5+}$ species. Catalytic tests demonstrated that the activity and selectivity to maleic anhydride increased with direct ultrasound technique.

\section{FINDINGS}

The crystallite size obtained was much smaller compared to the conventional while comprising well crystallised (VO) ${ }_{2} \mathrm{P}_{2} \mathrm{O}_{7}$ phase. Catalyst produced via direct ultrasound method were quite abundance of $\mathrm{V}^{4+}$ with slight $\mathrm{V}^{5+}$ present, because the ultrasonication produces strong convective currents which may lead to reduce in thickness of platelets of the catalyst revealing a better catalytic activity and selectivity. Thus, the catalysts in regardless of route prepared by direct ultrasound synthesis, were more reduced $\left(\mathrm{V}^{5+}\right.$ to $\left.\mathrm{V}^{4+}\right)$ and more polycrystalline nanometre particles, and indeed a large improvement in synthesis time to only 2 hours required for catalyst production.

\section{ACKNOWLEDGEMENT}

This research work is supported by Immortal Green Industrial Sdn. Bhd. was gratefully acknowledged. Resources support from JKS Engineering (M) Sdn. Bhd. was gratefully appreciated.

\section{REFERENCES}

1. Abon M, Volta J-C. Vanadium phosphorus oxides for $\mathrm{n}$-butane oxidation to maleic anhydride. Appl Catal A Gen. 1997;157(1-2):173-93.

2. Matsuura I, Ishimura T, Kimura N. Preparation and characterization of vanadyl hydrogen phosphate hydrates; $\mathrm{VO}(\mathrm{HPO} 4) \cdot 1.5 \mathrm{H} 2 \mathrm{O}$ and $\mathrm{VO}(\mathrm{HPO} 4) \cdot 0.5 \mathrm{H} 2 \mathrm{O}$. Chem Lett [Internet]. 1995 Sep;24(9):769-70. Available from: http://pubs.acs.org/doi/abs/10.1021/ja00338a020

3. Leong LK, Chin KS, Taufiq-Yap YH. Effect of varying reflux durations on the physico-chemical and catalytic performance of vanadium phosphate catalysts synthesized via vanadyl hydrogen phosphate sesquihydrate. Appl Catal A Gen [Internet]. 2012 Feb;415-416:53-8.

4. Pillai U, Sahle-demessie E, Varma RS. Alternative routes for catalyst preparation: use of ultrasound and microwave irradiation for the preparation of vanadium phosphorus oxide catalyst and their activity for hydrocarbon oxidation. Appl Catal A Gen [Internet]. 2003 Oct 8;252(1):1-8.

5. Griesel L, Bartley JK, Wells RPK, Hutchings GJ. Preparation of vanadium phosphate catalysts from VOPO4. 2H2O: Effect of VOPO4.2H2O preparation on catalyst performance. J Mol Catal A Chem. 2004;220(1):113-9.

6. Taufiq-Yap YH, Leong LK, Hussein MZ, Irmawati R, Abd Hamid SB. Synthesis and characterisation of vanadyl pyrophosphate catalysts via vanadyl hydrogen phosphate sesquihydrate precursor. Catal Today. 2004;93-95:715-22. 